\title{
Erratum to: Positive selection in octopus haemocyanin indicates functional links to temperature adaptation
}

Michael Oellermann ${ }^{1 *}$, Jan M. Strugnell ${ }^{2}$, Bernhard Lieb ${ }^{3}$ and Felix C. Mark ${ }^{1}$

\section{Erratum}

The original version of this article [1] unfortunately contained a mistake. The presentation of Table 1 along with the table legend and footnote was incorrect in the HTML and PDF versions of this article. The corrected version is given below.

\footnotetext{
Author details

${ }^{1}$ Integrative Ecophysiology, Alfred-Wegener-Institute Helmholtz Centre for Polar and Marine Research, Am Handelshafen 12, Bremerhaven 27570, Germany. ${ }^{2}$ Department of Genetics, La Trobe Institute for Molecular Sciences, La Trobe University, Bundoora 3086, VIC, Australia. Institute of Zoology, Johannes Gutenberg-Universität, Müllerweg 6, Mainz 55099, Germany.
}

Received: 9 November 2015 Accepted: 10 November 2015

Published online: 02 December 2015

\section{Reference}

1. Oellermann M, Strugnell JM, Lieb B, Mark FC. BMC Evol Biol. 2015;15:133. doi:10.1186/s12862-015-0411-4.

* Correspondence: oellermann.m@gmail.com

${ }^{1}$ Integrative Ecophysiology, Alfred-Wegener-Institute Helmholtz Centre for Polar and Marine Research, Am Handelshafen 12, Bremerhaven 27570, Germany

\section{Submit your next manuscript to BioMed Central and take full advantage of:}

- Convenient online submission

- Thorough peer review

- No space constraints or color figure charges

- Immediate publication on acceptance

- Inclusion in PubMed, CAS, Scopus and Google Scholar

- Research which is freely available for redistribution

Submit your manuscript at www.biomedcentral.com/submit 
Table 1 Positively selected sites in octopus haemocyanin at which at least three or more selection tests identified significant positive selection. Analysis was performed for two separate alignments, containing 113 or 126 sequences respectively, and covering in total a 396 amino acid long region of the haemocyanin's functional units $f$ and $g$. Numbering of positions refers to the published full haemocyanin sequence of Enteroctopus dofleini [UniProt: O61363] [23, 24]. Significance thresholds were: P $\leq 0.10$ for SLAC, $\leq 0.10$ for FEL, MEME and PRIME; Posterior Probability $\geq 0.90$ for FUBAR; Bayes Factor $\geq 0.50$ for EF. See Additional file 5 for detailed results

\begin{tabular}{|c|c|c|c|c|c|c|c|c|c|c|}
\hline \multirow[t]{2}{*}{ Residue } & \multirow[t]{2}{*}{$S L A C^{a}$} & \multirow[t]{2}{*}{$\mathrm{FEL}^{\mathrm{a}}$} & \multirow[t]{2}{*}{ MEME $^{a}$} & \multirow[t]{2}{*}{ FUBAR $^{a}$} & \multirow[t]{2}{*}{$\mathrm{EF}^{a}$} & PRIME $^{b}$ & \multicolumn{4}{|c|}{ TreeSAAP } \\
\hline & & & & & & & $\mathrm{pHi}$ & $\mathrm{pK}^{\prime}$ & $\mathrm{pa}$ & PCT \\
\hline 2383 & & * & * & & & & & $\downarrow(1) \uparrow(2-4)$ & & \\
\hline 2409 & * & * & * & * & * & & & & & \\
\hline 2410 & * & * & * & & & & & $\downarrow(5-8)$ & & \\
\hline 2442 & & & & & * & (CC) & & $\downarrow(10) \uparrow(5,9,11)$ & & \\
\hline 2469 & & & * & & & $\mathrm{CC}$ & & & $\downarrow(12,13)$ & \\
\hline 2496 & & $*$ & * & * & * & & $\downarrow(14,15)$ & & & \\
\hline 2503 & * & * & * & * & * & (P) & & & $\begin{array}{l}\downarrow(14,15,22-27) \\
\uparrow(20)\end{array}$ & \\
\hline 2545 & & & & * & * & & & $\begin{array}{l}\downarrow(4,20,28-30) \\
\uparrow(9,19,31,32)\end{array}$ & & \\
\hline 2575 & & & * & & * & & & & $\downarrow(33,34)$ & \\
\hline 2585 & & * & * & * & * & $\mathrm{pHi} \quad \mathrm{CC} \quad(\mathrm{P}) \quad(\mathrm{V})$ & & & & \\
\hline 2602 & & * & * & & & & $\downarrow(35,36)$ & & & $\uparrow(35,36)$ \\
\hline 2610 & & * & * & & & $\mathrm{pHi}$ & $\begin{array}{l}\downarrow(37-39) \\
\uparrow(40,41)\end{array}$ & & & $\begin{array}{l}\downarrow(40-42) \uparrow(37- \\
39)\end{array}$ \\
\hline 2643 & & & * & & & CC & & & & $\downarrow(38)$ \\
\hline
\end{tabular}

Abbreviations: $C C$ chemical composition, $P$ polarity, $V$ volume, $p H i$ iso-electric point, $p K^{\prime}$ equilibrium constant (ionization of $\left.C O O H\right), p a$ alpha helical tendencies, $P C T$ power to be at the C-terminal

${ }^{\text {a }}$ Sites at which SLAC, FEL, MEME, FUBAR or EF identified positive selection are indicated with asterisks

${ }^{b}$ Sites at which positive selection was inferred with PRIME. Properties under selection are indicated in bold letters and properties being conserved are indicated in parenthesis

'Sites at which positive selection was inferred with TreeSAAP. Magnitude of amino acid change was 8 for pHi and pK' and 6 for pa and PCT. Arrows indicate an increase $(\downarrow)$ or decrease $(\uparrow)$ of the amino acid property. Parenthesis mark the affected branches shown in Figure 3 